\title{
大ロ径 $\mathrm{Si}$ ウエハ表面形状の計測評価技術に関する研究*
}

\author{
一第 2 報：ウェーブレット变換を用いたノイズ除去手法の適用一 \\ 尾嶌 裕 隆 ${ }^{* *}$ 周立 波 ${ }^{* *}$ 清 水 淳 ${ }^{* *}$
}

Study on Surface Profile Evaluation for Large Si Wafer Measurement

- 2nd Report : Application of Denoising Method by Use of Wavelet Transform -

Hirotaka OJIMA, Libo ZHOU and Jun SHIMIZU

\begin{abstract}
In this research, we have been developing the denoising method by use of wavelet transform. In previous report, this method was investigated by comparison with conventional low-pass filter and Fourier transform. It was concluded that wavelet transform was more effective for elimination of white noise and this method was capable of removing the noise not only in the frequency domain, but also in amplitude domain. In this report, the denoising method by use of wavelet transform is applied into evaluation of $\mathrm{Si}$ wafer profile data which is acquired by an actual measurement system. As the acquired data includes not only the white noise but also the inherent noise introduced by the measurement system itself, it is found that the proposed method of filtering white noise in both frequency and amplitude domains is insufficient to improve GBIR (Global Backside Ideal Range which is also equal to peak-to-valley). The cutoffs used in the proposed method are then fine-turned via least-square procedure. The results demonstrate the validation of newly designed filter in GBIR improvement.
\end{abstract}

Key words: Si wafer, digital filter, noise, wavelet transform, profile measurement, denoising

\section{1. 緒言}

本研究では, ウェーブレット変換（WT: Wavelet transform）に

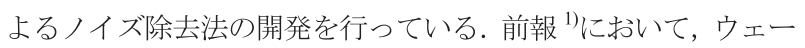
ブレット変換を用いたノイズ除去法の基礎的な検討を行った. シミュレーションにより, 計測時に発生したノイズは, 繰り返 し計測し平均值処理しても, バイアスとして GBIR（=peak-tovalley）に重冨し, サンプリングデータ数とともにその影響が大 きくなることを明らかにした．また従来のローパス・フィルタ と異なり, ウェーブレット変換が周波数成分および振幅成分の 両方に対してフィルタリングが可能で, 周波数成分と振幅成分 を同時に除去する手法がホワイト・ノイズの除去において最も 有効であることを示した.

そこで第 2 報である本報では, 前報で有用であることを示し たウェーブレット変換を用いたノイズ除去法により, 実際のウ エハ平坦度計測器で測定したデータからのノイズ除去を試みる. まず，実際のウエハ計測データにホワイト・ノイズが付加され ていると仮定した場合のノイズ除去の効果について比較する. 次に, 計測器固有のノイズ特性を取り出し, この特性を持つノ イズを除去できるフィルタを設計し，その効果を明らかにする.

\section{2. ウェーブレット変換によるノイズ除去法}

ここでは，まず前報で明らかにしたウェーブレット変換によ るノイズ除去の手法と効果について簡潔に述べ, 実際のウエハ 平坦度の計測データへの適用のために, ウェーブレット変換の 二次元化について説明する.

図 1(a)に振幅が 1 のサイン波に対して $\varepsilon(0,0.1)$ のホワイト・ノ

*原稿受付 平成 24 年 12 月 13 日

**正 会 員 茨城大学 (茨城県日立市中成沢町 4-12-1)

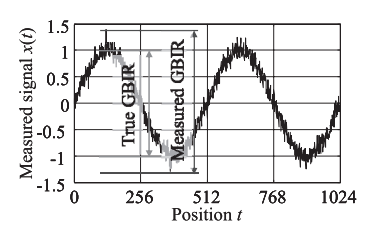

(a) input signal

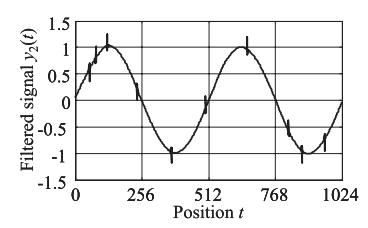

(c) $A_{c}=0.3$

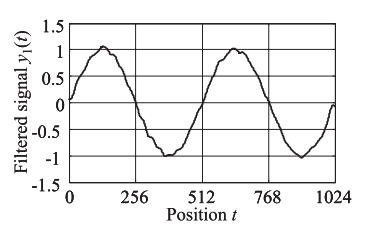

(b) $\lambda_{c}=40 \mathrm{pts}$

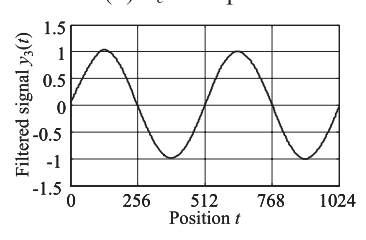

(d) $\lambda_{c}=40 \mathrm{pts}$ and $A_{c}=0.3$
Fig. 1 Results of denoising with WT

イズを付加したものを計測データとして示す. 真值 $\mathrm{GBIR}=2$ に 比べて，ノイズの存在によって計測した GBIR が大きくなって いることを定性的に見ることができる．前報の結果により，1） 繰り返し計測し平均值処理しても, GBIRに及ぼすノイズの影響 が消去されず，バイアスとしてプラスされること，2）このバイ アスはサンプリングデータの数と共に大きくなることがわかっ ている.このため, 計測データからノイズのみを適切に除去す るフィルタの開発が重要である.

図 1(b) (d)に, 前報で開発したウェーブレット変換によるホワ イト・ノイズの除去結果を示す. 図 1(b)は周波数成分に対寸る フィルタ（周波数フィルタとする）により高周波数のノイズ除 去を行った結果, 図 1(c)は振幅成分に対するフィルタ（振幅フ イルタとする）により低振幅のノイズ除去を行った結果, そし て図 1(d)が周波数成分と振幅成分を同時に考慮したフィルタ(周 波数・振幅フィルタとする) により, 高周波数かつ低振幅の) 


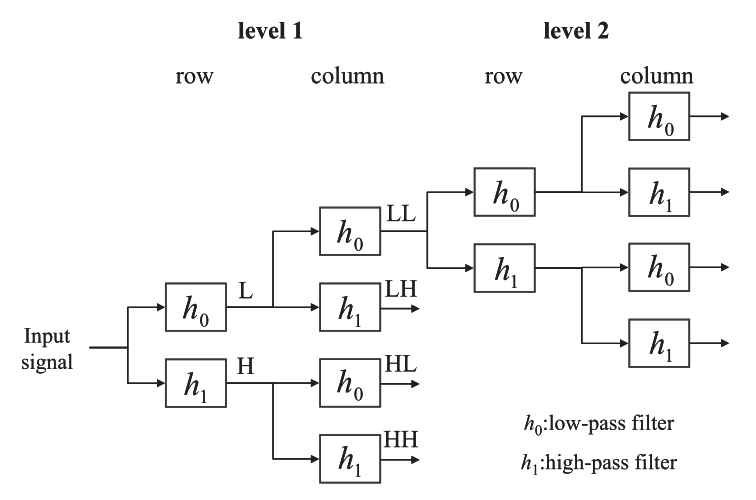

(a) Wavelet transform

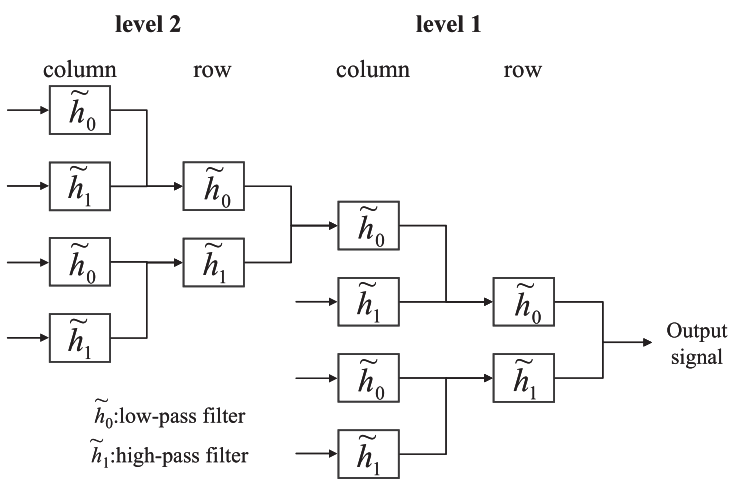

(b) Inverse wavelet transfrom

Fig. 2 2D Wavlet Transform

イズ除去を行った結果を示している. これらの結果からわかる ように, 周波数成分のみ, 振幅成分のみでは十分にノイズ除去 が行われていない，それに対し，高周波数でなおかつ低振幅の 成分を除去するフィルタでは, 周波数フィルタのみ, または振 幅フィルタのみの場合に比べ, 除去成分が少ないにもかかわら ず, 最も効果的に高周波数・低振幅のノイズ除去が行われてい る.

このウェーブレット変換を用いたノイズ除去手法を, 実際の ウエハ平坦度計測データに適用するため, 二次元に拡張する. まず，一次元の離散 WT は以下の式により定義される.

$$
X(\ell, k)=\sum_{n} x(t) \psi_{\ell, k}(t)
$$

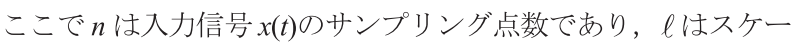
リング係数, $k$ はシフト係数を表し, 離散 WT の空関数 $\psi(t)$ は マザーウェーブレットと呼ばれ，式(2)で与えられる2).

$$
\psi_{\ell, k}(t)=2^{-\ell / 2} \psi\left(2^{-\ell} t-k\right)
$$

上記の式(1), (2)により入力信号 $x(t)$ とウェーブレット $\psi(t)$ との 相関值であるウェーブレット係数 $X(\ell, k)$ が計算され, 波長が $2^{\ell}$ に相当する周波数成分を抽出することが出来る. この処理を順 次行うことにより, 入力信号 $x(t)$ が高周波成分と低周波成分に分 解される. 分解するにつれて, $\ell$ が大きくなり, より低周波の成 分に分解される.この分解の度合いを level $\ell$ で表す. 図 2 に二 次元信号に適用する際の WT および逆ウェーブレット変換

(IWT: Inverse wavelet transform) の処理方法を示す. 上記一次元 の WT をまず二次元信号の行方向について適用し, それによっ て得られた高周波成分（H 成分と寸る）と低周波成分（L 成分 とする）それぞれについて, 列方向に再びWT を行う. H 成分 に対寸る列方向の分解により $\mathrm{HH}$ 成分と HL 成分に, また L 成 分に対する列方向の分解により LH 成分と LL成分に分解される ため, level 1 のWTにより, 元の信号は 4 つの周波数成分に分 解される. その中で LL 成分に対して再帰的に行, 列方向の WT を行うことにより，さらに分解される. IWT については，この 処理手順とは逆になり, 列方向に対して IWT を行い, 続けて行 方向に IWT を行うことにより,一つ上の level $(\ell-1)$ の成分を再 構築することが出来る ${ }^{3) ~ 4)}$.

この IWT の際に, ウェーブレット係数に対して次のような処 理を行うことによりノイズ除去を実現する．前報において，ウ エーブレット係数に対するノイズ除去では, 次の式によるハー ド閾值処理が優れていた．本報告においてもハード閾值処理を 用いる. まず周波数フィルタの場合, 入力ウェーブレット係数

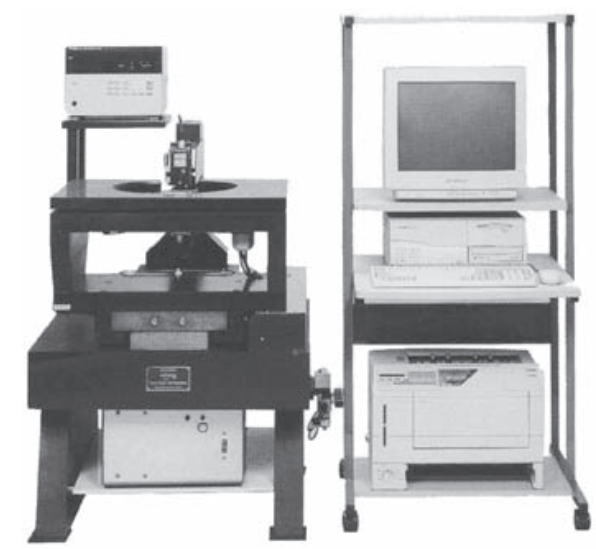

Fig. 3 Measurement system

Table 1 Specification of Lasor profiler

\begin{tabular}{c|c}
\hline Measurement principle & triangulation method \\
\hline Spot size & $10-18 \mu \mathrm{m}$ \\
\hline Measurement range & $160 \mu \mathrm{m}$ \\
\hline Working distance & $8 \mathrm{~mm}$ \\
\hline \hline Height resolution & $0.005 \mu \mathrm{m}$ \\
\hline Repeatability & $\pm 0.08 \mu \mathrm{m}$ \\
\hline \hline Linearity & $\pm 0.03 \% \mathrm{MR}$ \\
\hline Sampling period & $15.6 \mu \mathrm{s}$ \\
\hline
\end{tabular}

$X(\ell, k)$ に対して, 出力ウェーブレット係数 $X_{T}(\ell, k)$ は次式で表さ れる.

$$
X_{T}(\ell, k)=\left\{\begin{array}{cc}
X(\ell, k) & \left(\ell>\ell_{0}\right) \\
0 & \left(\ell \leq \ell_{0}\right)
\end{array}\right.
$$

ここで, $\ell_{0}$ はカットオフ波長 $\lambda_{c}=2^{\ell_{0}} / 0.345$ に関わる分解レベ ルである. また, 振幅フィルタの場合, 次の式に従って閾值処 理が行われる.

$$
X_{T}(\ell, k)=\left\{\begin{array}{cc}
X(\ell, k) & \left(|X|>T_{c}\right) \\
0 & \left(|X| \leq T_{c}\right)
\end{array}\right.
$$

ここで, $T_{c}$ は振幅のカットオフ閾值であり, 必要に応じて任意 に決定できるが, ノイズの標準偏差 $\sigma$, 入力信号のサンプル数が $N$ の時, $T_{c}=\sigma \sqrt{2 \log _{2} N}$ で与えられる場合が多い ${ }^{5)}$. 上記の式 
(3)や(4)により閾值処理されたウェーブレット係数を IWT 時に 用いることで，ノイズ除去された信号を得ることが出来る。ま た，周波数・振幅フィルタでは，式(3)および(4)を同時に用いる ことによりノイズ除去を行い，良好な結果が得られている ${ }^{1)}$.

\section{3. 実験装置および計測方法}

図 3 に本研究で用いたウエ八計測装置の外観写真を, また表 1 には装置で用いられているレーザープロファイラの仕様を示す. このウエ八計測装置は, 図 4 に示寸ように, ウエ八を挟んで上 下に 2 台レーザープロファイラを配置し, ウエハを回転させな がらレーザープロファイラを外周から中心へと移動させること により，ら旋状にウエ八全面の厚さの計測を行うものである. ら旋状に計測時のサンプリングピッチは 1 $5 \mathrm{~mm}$ で 5 段階に選択 可能となっている. 本装置を用いた直径 $300 \mathrm{~mm}$ のウエハをサン プリングピッチ $3 \mathrm{~mm}$ で計測したデータの一例を図 5 に示す. 計 測に用いたウエハは直径 $300 \mathrm{~mm}$ に対し，厚さの計測結果は厚さ $771.924 \sim 772.135 \mu \mathrm{m}$ と peak-to- valley $=0.211 \mu \mathrm{m}$ にあり, 非常に平 坦であることがわかる．また，上記の非常に小さな範囲内でも ウエ八全体の凹凸形状がわかるほどに精密な計測が行われてい る.しかし，この計測結果においてもノイズが存在しており， このノイズを除去しなければ正確な計測結果が得られない。そ こで，この計測データに対し，WTによるノイズ除去を行う.

\section{4. 計測データに含まれるホワイト・ノイズ除去}

まず，計測データに含まれるノイズがホワイト・ノイズであ ると仮定し，ノイズ除去を行った. WT を用いたフィルタについ て, 周波数フィルタ, 振幅フィルタ, そして周波数・振幅フィ ルタを設計し，ノイズ除去を行った．それぞれのフィルタにお ける, カットオフ波長 $\lambda_{c}$, カットオフ閾值 $T_{c}$ は, 前報での設計 方法に従い, $\lambda_{c}=23.2 \mathrm{~mm}\left(\ell_{0}=3\right), T_{c}=0.0015$ とした. 3 種類の フィルタによるノイズ除去結果を, それぞれ図 6 8 に示す. 図 6〜8において, (a)はノイズ除去後のウエハ形状, (b)は除去した ノイズ成分，(c)は除去したノイズ成分のヒストグラムを示し, また(c)の実線はヒストグラムに近い正規分布の近似曲線を表し ている.

図 6 では, カットオフ波長 $\lambda_{c}=23.2 \mathrm{~mm}$ で高周波成分をノイズ として除去しているが, 図 5 と図 6(a)を比較すると全体的に形 状が除去されていることがわかる.ささら図 6(b)の除去された 成分から, 除去量が多いことが見てとれ，ホワイト・ノイズの みでなく同心円状の形状成分が全体的に含まれていることがわ かる.

図 7 の結果は, カットオフ閾值 $T_{c}=0.0015$ として, 低振幅成 分をノイズとして除去したものである. 図 6 と同様に, ノイズ だけでなく形状も除去されているため, 図 7(b)のように, 同心 円状の形状成分が見られる.

図 8 はカットオフ波長 $\lambda_{c}=23.2 \mathrm{~mm}$, カットオフ閾値 $T_{c}=0.0015$ とした高周波かつ低振幅の成分をノイズとして除去した結果と なっている. 図 6,7 と比べ, 図 8(b)の除去ノイズ成分は全体的 にまんべんなく現れており, 前出の 2 つの結果と異なり, 同心 円状の形状成分はあまり現れずにノイズのみの除去ができてい る. 図 8(c)のヒストグラムにおいても標準偏差が小さく, 除去 ノイズ成分が低振幅成分に集中していることがわかる.

これら図 6 8(c)の除去されたノイズのそれぞれの平均值 $M$, 標準偏差 $\sigma$, 尖度 $K w$, 歪度 $S k$ をまとめ, 表 2 に示す. このフィ

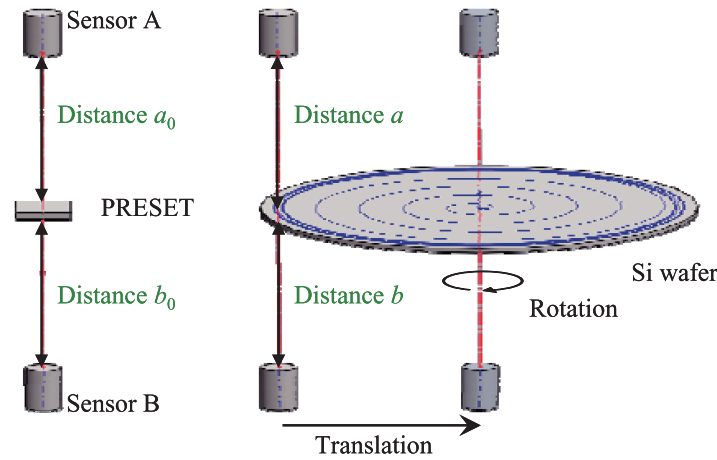

Fig. 4 Measuring scheme of measurement system

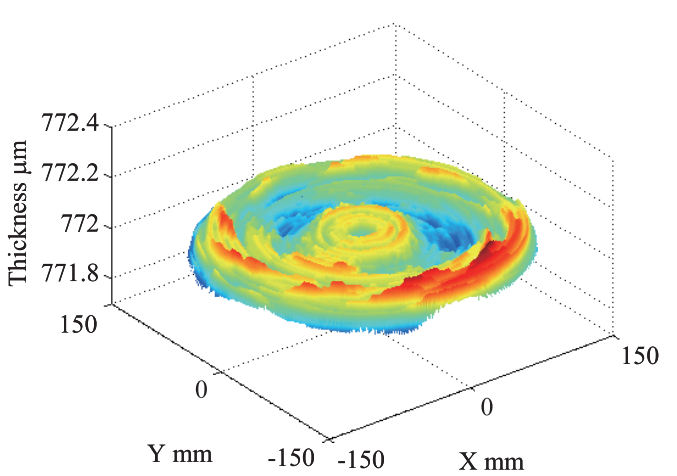

Fig. 5 Measured wafer data

Table 2 Characteristics of removed noise

\begin{tabular}{c|c|c|c||c|c}
\hline & $M[\mu \mathrm{m}]$ & $\sigma[\mu \mathrm{m}]$ & $K w$ & $S k$ & GBIR $[\mu \mathrm{m}]$ \\
\hline \hline$\lambda_{c}=23.2 \mathrm{~mm}$ & $-4.6 \times 10^{-4}$ & 0.0078 & 5.25 & -0.85 & 0.164 \\
\hline $\begin{array}{c}\text { Hard threshold } \\
\left(T_{c}=0.0115\right)\end{array}$ & $-2.2 \times 10^{-6}$ & 0.0073 & 0.21 & -1.33 & 0.207 \\
\hline $\begin{array}{c}\lambda_{c}=23.2 \mathrm{~mm} \& \\
\text { Hard threshold } \\
\left(T_{c}=0.0115\right)\end{array}$ & $-5.9 \times 10^{-5}$ & 0.0041 & 0.49 & -0.037 & 0.211 \\
\hline
\end{tabular}

ルタでは, ホワイト・ノイズを対象としたノイズ除去を行った ため, 平均值, 尖度, 丕度は全て 0 になることが望ましい. 表 2 より, 全てのフィルタにおいて, 平均值はほぼ 0 となっている ことがわかる. しかし，周波数フィルタでは，尖度が大きくな っており，ノイズ以外に振幅の大きな形状まで除去されている と考えられる.この表 2 より, 周波数・振幅フィルタが実際の 計測データに対するノイズ除去においても, 最も良くホワイ ト・ノイズを除去できていることがわかる.

また, GBIRについてノイズ除去前後で比較をすると, ノイズ 除去前の図 5 では, GBIR $=0.211 \mu \mathrm{m}$ となっているが, 図 6, 7, 8(a)ではそれぞれ $0.164 \mu \mathrm{m}, 0.207 \mu \mathrm{m}, 0.211 \mu \mathrm{m}$ となっている. 図 6,7 の周波数フィルタまたは振幅フィルタでは除去前に比心゙ GBIR が小さくなっているが, 図 8 のホワイト・ノイズのみ除去 した場合では，ほとんど変わらなかった，ホワイト・ノイズを 除去しただけでは, GBIR を改善するまでには至らなかった. そ こで, 次に計測システムに含まれる固有のノイズについても除 去することを考える. 


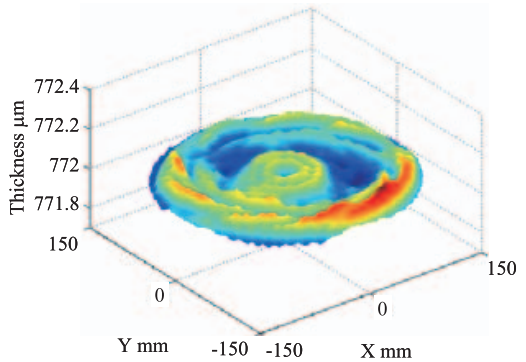

(a) Filtered data

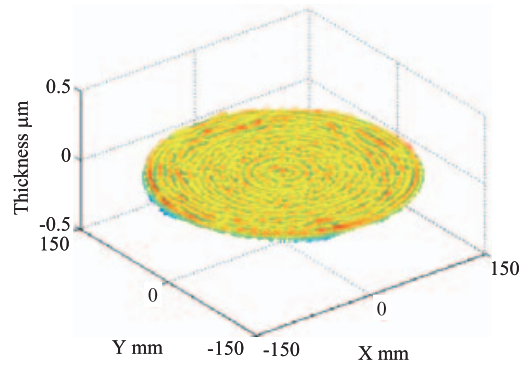

(b) Removed noise

Fig. 6 Filtered by LS WT with $\lambda_{c}=23.2 \mathrm{~mm}$

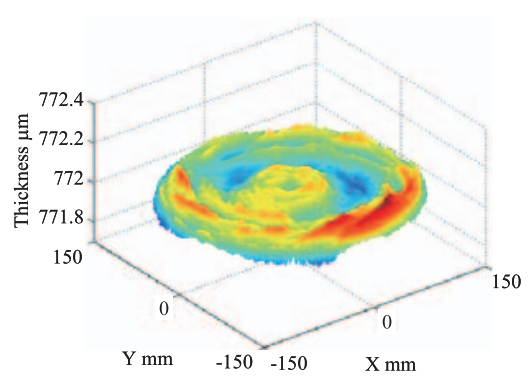

(a) Filtered data

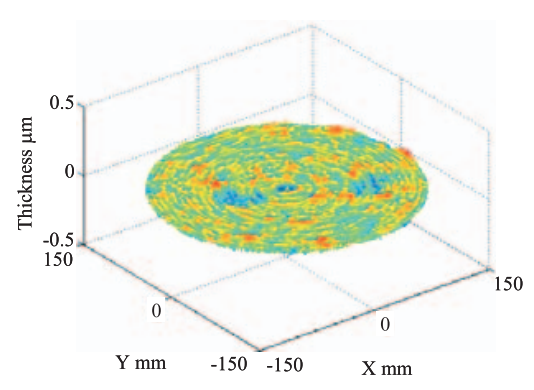

(b) Removed noise

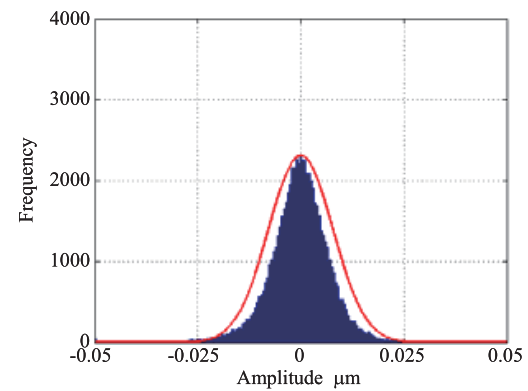

(c) Histogram of removed noise

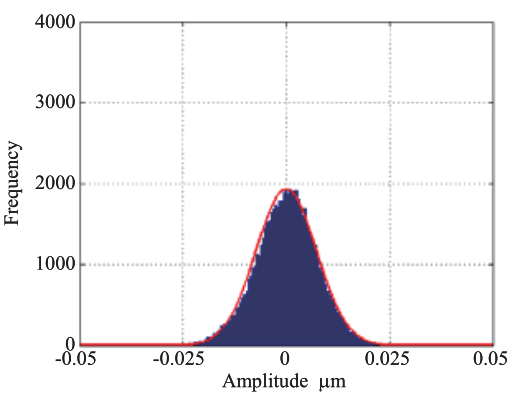

(c) Histogram of removed noise

Fig. 7 Filtered by LS WT with hard threshold $T_{c}=0.0115$

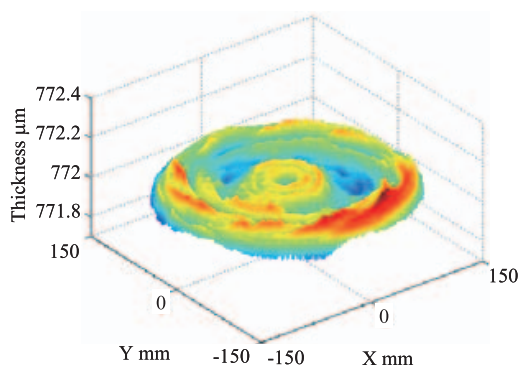

(a) Filtered data

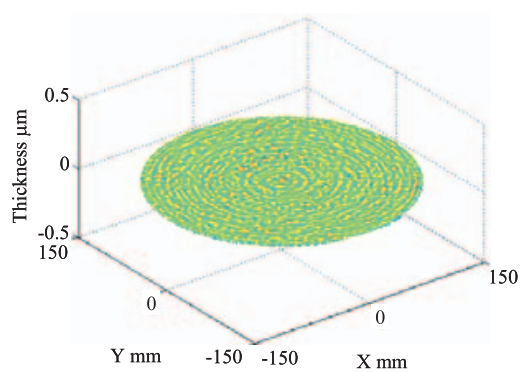

(b) Removed noise

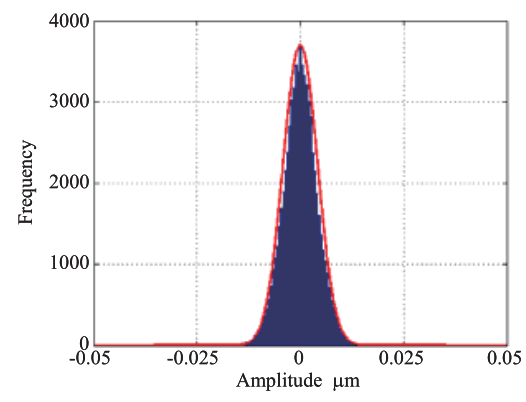

(c) Histogram of removed noise

Fig. 8 Filtered by LS WT with combined method $\lambda_{c}=23.2 \mathrm{~mm}$ and $T_{c}=0.0115$

\section{5. 計測データに含まれる装置固有のノイズ除去}

次に, 図 3 に示した計測システム固有のノイズ成分を除去す ることを考える．まず，固有のノイズ成分を以下のようにして 求める. 図 9 左図のように, 同一ウエ八に対して 150 回繰り返 し計測し, 150 回の計測データを取得する. それらのデータを計 測点ごとに平均を取り, 図 9 中央図のようにウエ八の平均デー 夕を取得する。この平均データは個々の計測点については繰り 返し計測によりノイズの影響がほぼなくなっていると考えられ るため, はじめに取得した 150 回の計測データからこの平均デ ータを差し引くことによって, 図 9 右図のように 150 回のノイ ズデータが取得できる.このようにして求めたノイズデータの 平均を取ることで, 計測システム固有のノイズ特性を求めた. 計測システム固有のノイズ特性のパラメータは, それぞれ平均 值 $M_{0}=-3.32 \times 10^{-3}$, 標準偏差 $\sigma_{0}=0.00673$, 尖度 $K w_{0}=0.314$, 歪度 $S k_{0}=0.0214$ となった.

この求めた特性のノイズを除去できるフィルタを設計する. ウエ八の平均データの $\mathrm{GBIR}$ を求めると $G B I R_{\text {mean }}=0.3716 \mu \mathrm{m}$ であ った。この平均データは，前述のとおりノイズの影響がほぼな
いものと考えられるため, 計測データのノイズ除去後の GBIR がこの GBIR mean $_{\text {に }}$ 近ければノイズが除去できたと考えられる. ノイズ除去後データの GBIR を GBIR fittered 測データから次式が最小となるようにフィルタの設計を行った。

$$
D=\sum_{n=1}^{150}\left(G B I R_{\text {filtered }}-G B I R_{\text {mean }}\right)^{2}
$$

設計パラメータは, 周波数・振幅フィルタのカットオフ波長 $\lambda_{c}$ とカットオフ閾值 $T_{c}$ となる. $\lambda_{c}$ と $T_{c}$ を以下のように数值シミュ レーションを行って求めた. 本シミュレーションでは, $\lambda_{c}$ は WT

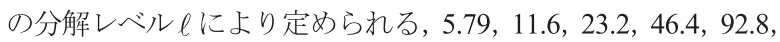
$185.5 \mathrm{~mm}$ の 6 つの值のみを用いる. また $T_{c}$ は試行錯誤的に 0.01 〜 0.10 の範囲を用いた. この数值計算により, $G B I R_{\text {filtered }}=0.3716$ となるカットオフ波長, カットオフ閾値は, それぞれ $\lambda_{c}=46.4 \mathrm{~mm}$, $T_{c}=0.0242$ と求められた. そのときの GBIR のヒストグラムにつ いて図 10 に示す.図10(a)は150回の計測データそのものの GBIR のヒストグラム, 図 10(b)は求めた $\lambda_{c}, T_{c}$ によるノイズ除去後の GBIR のヒストグラムである. 2 本の垂直線はそれぞれ, 実線 が図 9 の平均データの $G B I R_{\text {mean }}$, 点線がヒストグラムの平均 GBIR となっている. 図 10(a)の GBIR の平均值は $0.3770 て ゙$, 
$<$ Raw data $>$

sampling data \# 1

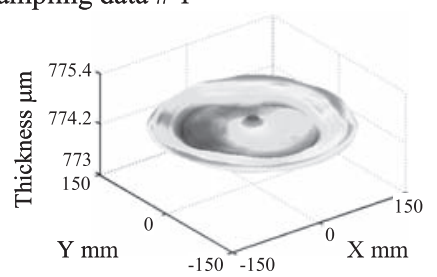

sampling data \#150

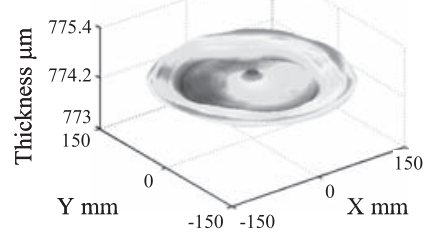

$<$ Mean $>$

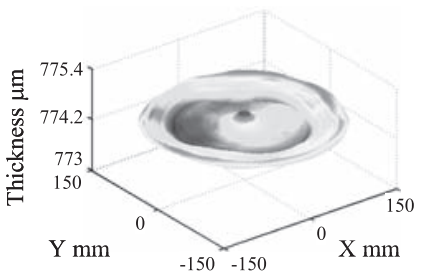

$<$ Inherence noise $>$

noise 1

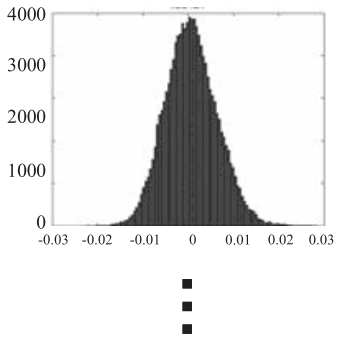

noise 150

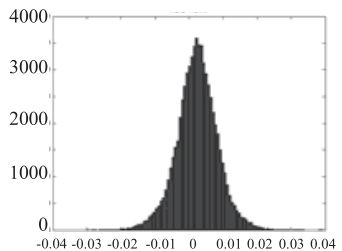

Fig. 9 Method for identifying the noise of actual machine

$G B I R_{\text {mean }}$ にノイズによるバイアスを付加されていることがわか り, (b)においてノイズ除去後の GBIR の平均值と $G B I R_{\text {mean }}$ がほ ぼ一致していることが確認できる. このように, 周波数・振幅 フィルタのカットオフ波長, カットオフ閾値を $\lambda_{c}=46.4 \mathrm{~mm}, T_{c}=$ 0.0242 に微調整すれば，計測システム固有のノイズ成分にも対 応可能なフィルタを設計でき, GBIR の改善が達成できた。 しか し, GBIR の標準偏差は, ノイズ除去前 0.0103 に対し, ノイズ 除去後が 0.0124 とほぼ変わらない結果となった.

\section{6. 結言}

本論文で得た結果を，以下のようにまとめる.

(1) ウェーブレット変換を用いたノイズ除去フィルタを 2 次元 に拡張し, 大口径 Si ウエハ表面形状の計測評価に適用可能 とした.

（2）実際のウエハ計測データに対しノイズ除去を行った. ホワ イト・ノイズが含まれる場合, 周波数・振幅フィルタによ り除去されたノイズの特性が, 平均值 $M=-5.9 \times 10^{-5}$, 尖度 $K w=0.49$, 歪度 $S k=-0.037$ といずれもほぼ 0 であり, この周 波数・振幅フィルタが最もノイズ除去に適していることを 明らかにした。

(3) ウエハ計測システム固有のノイズを求めた. また最小自乘 法によりバンド・振幅フィルタのカットオフ波長, 閾值を $\lambda_{c}=46.4 \mathrm{~mm} ， T_{c}=0.0242$ と設計することで，ノイズによる バイアスをほぼ 0 にでき, GBIR の改善をすることが出来 た. 一方, GBIR の標準偏差は除去前後において変化が見 られなかった。

$$
\text { 謝辞 }
$$

本研究は平成 23 年度文部科学省科学研究費（課題番号 23360062) および平成 24 年度文部科学省科学研究費（課題番号 24760099）の助成により行われたことを記し，謝意を表す.

\section{参 考 文 献}

1) L. Zhou et al.: Study on Surface Profile Evaluation for Large Si Wafer Measurement $-1^{\text {st }}$ Report : Denoising by Use by Wavelet Transform -, J. Jpn.

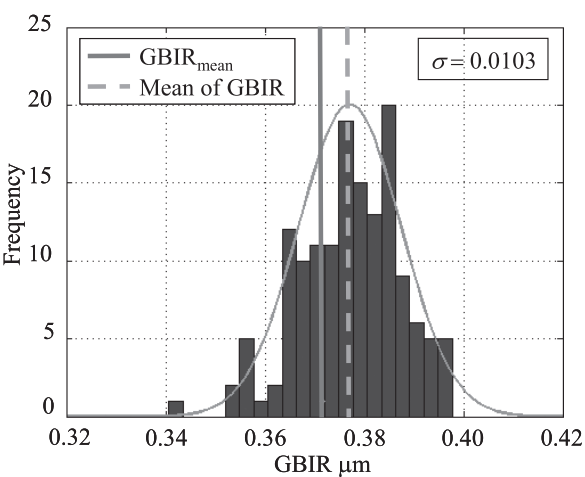

(a) Raw data

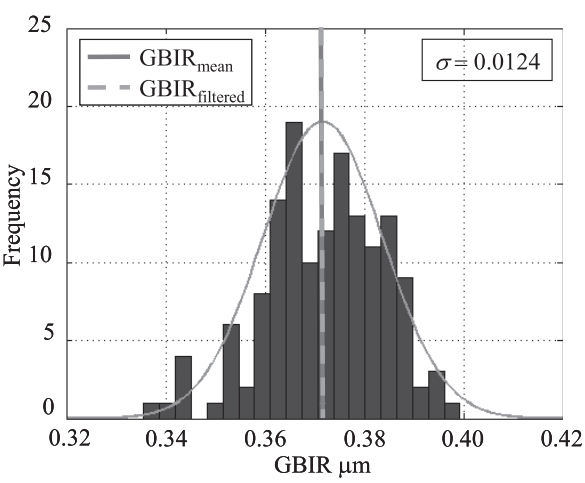

(b) Filtered data

Fig. 10 Histgram of GBIR

Soc. Precis. Eng., 77, 12, (2011) 1165 (in Japanese).

2) X. Jiang, et al.: Wavelets and their application for surface metrology, CIRP Annals - Manufacturing Technology 57 (2008) 555.

3) M. Mitani: Communication mathematics for "doing over", CQ Publishing Co.,Ltd. (2008) 157 (in Japanese).

4) O Rioul, and M Vetterli: Wavelets and Signal Processing, IEEE Sig. Proc. Mag., (1991) 14.

5) D L Donoho, I M Johnston: Ideal Spatial Adaptation by Wavelet Shrinkage, Biometrika, 81, 3, (1994) 425 . 